\title{
Pibid Diversidade: experiência fortalecedora na Licenciatura em Educação do Campo da UnB - Planaltina $-\mathrm{DF}$
}

SOUSA, Rosineide Magalhães de ${ }^{1}$

\section{RESUMO}

Este artigo traz a experiência do Pibid Diversidade, da CAPES, na Licenciatura em Educação do Campo (LEdoC), da Universidade de Brasília, Campus Planaltina - DF, no período de 2014 ao início de 2018, como política pública de fortalecimento à formação inicial docente. Para este trabalho, são utilizados conhecimentos da área de Educação do Campo e dos Letramentos como prática social, com olhar de uma leitura etnográfica. Tem como contexto principal as escolas de Educação Básica do Campo (da região Centro-Oeste), com ênfase na construção da organização escolar e do trabalho pedagógico para os anos finais do Ensino Fundamental e para o Ensino Médio. Com o objetivo de formar educadores para atuarem na Educação Básica em escolas do campo, simultaneamente, contribuiu para a construção coletiva de um projeto de formação de educadores que sirva como referência a políticas de Educação do Campo. O projeto do Pibid Diversidade, para esse curso, tem, ainda, o objetivo primordial de promover os letramentos múltiplos (leitura e escrita dos diferentes conhecimentos e linguagens, associando diferentes áreas do conhecimento em um trabalho multidisciplinar) dos licenciandos e das escolas do campo. O Pibid Diversidade ampliou as possibilidades da formação de qualidade dos futuros docentes, promovendo a inserção deles na escola desde o início da licenciatura, possibilitando uma experiência de práxis pedagógica.

Educação do Campo. Pibid Diversidade. Formação inicial de professores. Letramentos Múltiplos.

Pibid Diversidade: a reinforced experience in the Rural Education Graduation of the UnB - Planaltina - Federal District

\section{ABSTRACT}

This article brings the experience of the Pibid Diversidade (Institutional Program of Scholarship for the Introduction to Teaching: Diversity), of CAPES, degree in the rural education (LEdoC) of the University of Brasília, Planaltina Campus -

\footnotetext{
${ }^{1}$ Professora Adjunta da Universidade de Brasília - UnB, lotada no campus de Planaltina - DF e Programa de Pós-Graduação de Linguística - PPGL/UnB. Foi coordenadora institucional do PIBID Diversidade - UnB/CAPES, de 14 a 2018. É Pesquisadora do Observatório da Educação do Campo, da CAPES. É lider do grupo de pesquisa SOLEDUC, certificado pelo CNPq.
} 
Federal District, in the period from 2014 to the beginning of 2018, as a public politic of reinforcement of the initial teachers education. To this work, we use the knowledge in the Rural Education field and the literacy as a social practice, looking through an ethnographic reading. Brought as a main context, schools of basic education of the countryside (in the Midwest region), with emphasis in the construction of the scholar organization and the pedagogic work to the final years of the elementary school and to the high school. The objective of educating teachers to act in the basic education in rural schools, simultaneously, contributed to the collective construction of a project of teachers education that fits as a reference to rural education politics. The project of Pibid Diversidade, to this course, has had the primordial objective of promoting the multiples literacies (reading and writing of different knowledge and languages, connecting different fields of knowledge in a multidisciplinary work) of the graduating students and the rural schools. The Pibid Diversidade widened the possibilities of education with quality to the future teachers, furthering their insertion in the school since the start of the graduation, making possible an experience of a pedagogic praxis.

\section{Rural Education. Pibid Diversidade. Initial Teachers Education. Multiple} Literacies.

\section{INTRODUÇÃO}

Este artigo apresenta, de forma sintética, a experiência do Pibid Diversidade, Programa Institucional de Bolsa de Iniciação à Docência, da CAPES, Coordenação de Aperfeiçoamento de Pessoal de Nível Superior, do Departamento de Educação Básica, na Licenciatura em Educação do Campo (LEdoC), da Universidade de Brasília, Campus Planaltina - DF, no período de 2014 ao início de 2018, como política pública de fortalecimento à formação inicial docente. Por meio dessa política pública foi possível se aproximar, com uma leitura mais precisa, da realidade das escolas do campo em sua dinâmica pedagógica, que é diferente de muitas escolas urbanas, por serem distantes das casas dos estudantes, necessitando de transporte escolar, que nem sempre cumpre a contento seu papel. Há, ainda, fatores ambientais, de gestão municipal ou estadual que influenciam na educação das crianças e do jovens do campo, que não são o foco temático aqui. Para este discurso, são utilizados conhecimentos da área de Educação do Campo e dos Letramentos como prática social, com olhar de uma leitura etnográfica.

A LEdoC é o contexto do Pibid Diversidade. O Curso atende à demanda formulada pelo Ministério da Educação, por intermédio da Secretaria de Educação Superior e da Secretaria de Educação Continuada Alfabetização, Diversidade e Inclusão (SECADI). Tem como contexto principal as escolas de Educação Básica do Campo (da região Centro-Oeste), com ênfase na 
construção da organização escolar e do trabalho pedagógico para os anos finais do Ensino Fundamental e para o Ensino Médio. Com o objetivo de formar educadores para atuarem na Educação Básica em escolas do campo, simultaneamente, contribuiu para a construção coletiva de um projeto de formação de educadores que sirva como referência a políticas de Educação do Campo.

Hoje, essa licenciatura já registra 13 turmas: 7 concluídas e 6 em andamento. A metodologia do curso é a Pedagogia da Alternância, com o Tempo Universidade (na Universidade) e o Tempo Comunidade (na comunidade), este quando os alunos desenvolvem atividades de inserção orientada na escola e na comunidade desde o primeiro semestre do curso, que totalizam 8 semestres para todo o curso. O Pibid Diversidade subsidiou 0 tempo comunidade de muitos estudantes da LEdoC e fortaleceu a formação inicial deles, garantindo sua participação nas escolas do campo, muitas delas de difícil acesso, desde o início da formação e, também, contribuindo com essas escolas.

O projeto do Pibid Diversidade para esse curso tem o objetivo primordial de promover os letramentos múltiplos (leitura e escrita dos diferentes conhecimentos e linguagens, associando diferentes áreas do conhecimento em um trabalho multidisciplinar) dos licenciandos e das escolas do campo e, ainda, das comunidades onde os bolsistas desse projeto atuam. Ações desenvolvidas neste projeto abarcam o tempo universidade dos alunos, quando eles têm a oportunidade de participar de oficinas de letramento, de numeramento, de seminários de pesquisa, de saídas de campo e atividades culturais. E, também, o tempo comunidade, quando os bolsistas e colaboradores desenvolvem atividades que promovem os múltiplos letramentos na escola e na comunidade, como realização de seminários de ensino, encontros culturais, aula in situ, projetos multidisciplinares, pesquisa, encontros para discutirem temas que afetam sua realidade, políticas públicas voltadas para a Educação do Campo e, principalmente, atuarem nas escolas da educação básica do campo, na rotina da escola com todo seu processo pedagógico e social.

O Pibid Diversidade tem contribuído sobremaneira para a permanência de muitos educandos na universidade, pois há uma carência de recursos financeiros dessas pessoas para continuar seus estudos acadêmicos. O projeto amplia as possibilidades da formação de qualidade dos futuros docentes, promovendo a inserção deles na escola no início da licenciatura.

Como contribuições imediatas, tem-se a realização de pesquisas dos bolsistas, projetos comunitários específicos para cada comunidade e escola, conforme as suas necessidades e de acordo com os subprojetos de Linguagem e de Ciências da Natureza e Matemática. 
Mediante aos conhecimentos oriundos das pesquisas e das práticas pedagógicas, que se deram por meio do Pibid Diversidade, os estudantes em formação estão mais aptos a observar, analisar e atuar na transformação da escola, buscando uma educação básica de qualidade.

\section{A Educação do Campo}

A Educação do Campo nasceu da luta de pessoas, desse território, que defendem uma educação contra hegemônica, pautada na relação conjugada entre teoria e prática, isto é, o movimento da práxis, para atender à demanda dos sujeitos que vivem no campo. Nasceu, também, da denúncia e de reivindicações organizadas contra o cenário atual do campo, que sofre com a exploração do agronegócio. Segundo Molina e Hage:

as reivindicações dos movimentos sociais quanto às políticas e
práticas de formação docente priorizam a formação humana
dos educadores do campo, a fim de se colocar como agente
participativo na construção de um novo projeto de
desenvolvimento para o País, que afirme o lugar do campo
nesse novo projeto. E, a partir de intensas lutas por direitos,
que tem como elementos centrais o direito à terra e à
educação, o Movimento da Educação do Campo conquista
uma política específica de formação de educadores, porém
sem descolar essa política do conjunto das tensões e
contradições nas quais serão executados os processos de
formação que ficarão sob a responsabilidade desses
educadores. (2015, p. 133).

Nessa perspectiva, desenhamos um novo perfil de educador que vem do discurso e da prática da luta dos movimentos sociais camponeses, que buscam contribuir, de diferentes maneiras, com a transformação da atual escola do campo, aproximando-a das reais necessidades de seus sujeitos, fazendo, de fato, essa nova escola do campo que ofereça subsídios, que auxiliem os educandos camponeses a resistir a intensa desterritorialização, que the é imposta de diversos modos pelo avanço cada vez mais intenso do agronegócio, seja através da fagocitose das escolas do campo; seja através do arrendamento dos lotes da Reforma Agrária para diferentes monoculturas; seja disputando os territórios quilombolas através da exploração mineral ou dos empreendimentos turísticos, que buscam avançar sobre suas terras.

De acordo com Caldart (2002), as pessoas do campo devem ser protagonistas das ações voltadas para uma educação contextualizada ao seu território e não passivas às ações de educação imposta pelas políticas públicas hegemônicas. Visto que, esses sujeitos participam de experiências próprias de sua realidade social, e a escola precisa atender a essa realidade. Dessa forma, 
esse movimento configura a identidade do povo do campo que luta por uma educação por meio de políticas públicas que garantam o seu direito à educação que seja no e do campo. Isso significa que no campo, o povo tem direito a ser educado no lugar onde vive e do campo, o povo tem direito a uma educação planejada desde o seu lócus e com a sua participação, vinculada à sua cultura e às suas necessidades humanas e sociais. (CALDART, 2002).

Esse anseio dos povos do campo reflete nas características de políticas públicas inovadoras de formação de educadores, duas no âmbito da formação inicial e uma na formação continuada. Diferentes elementos do Programa de Apoio às Licenciaturas em Educação do Campo - PROCAMPO, vinculado à SECADI-MEC; do PIBID Diversidade e do Observatório da Educação, dois programas ligados à CAPES.

\section{Licenciatura em Educação do Campo}

As Licenciaturas em Educação do Campo são concretização de uma política pública voltada à formação docente, especificamente o docente do campo. Essa política é o resultado da luta dos povos do campo, que reivindicaram uma escola que, de fato, fosse estruturada, considerando os conhecimentos e as realidades desse território. Para se chegar a essa política pública de formação de educadores muitas batalhas foram travadas em um país onde a educação não é prioridade.

Atualmente, são 42 Licenciaturas em Educação do Campo espalhadas pelo Brasil, onde elas têm lugar nas universidades públicas. Conforme Molina e Sá:

A criação desta nova modalidade de graduação, que se estrutura em instituições de ensino superior no Brasil a partir de 2007, é resultado da luta dos movimentos sociais e sindicais que conquistam uma política de formação inicial para educadores do campo, materializada através do Programa de Apoio às Licenciaturas em Educação do Campo - Procampo, vinculadas à Secretaria de Educação Continuada, Alfabetização e Diversidade - SECADI, do Ministério da Educação. (2011, p. 13).

A formação inicial de professores é um tema que não se esgota, não sai de moda do discurso da sociedade. Muitas pessoas opinam sobre a formação de professores, conforme sua realidade social, mas sem ter uma experiência concreta dessa realidade, a não ser a sua própria realidade contextual. Há anos políticas públicas para essa formação, inventadas e reinventadas, com êxito ou sem êxito, com discussões amplas ou pouca discussão restrita a grupos dominantes, são postas e retiradas da educação escolar. 
Nas revistas semanais, nos jornais, na internet, nas monografias, nas dissertações, nas teses, nos artigos científicos, nas conversas informais, esse tema é sempre recorrente. Contudo, apesar de sua ampla abordagem, ainda, a formação docente precisa ser muito discutida, visto que o Brasil tem uma população jovem que precisa de uma escola qualificada, no sentido de oferecer uma educação que acompanhe as transformações dinâmicas de uma sociedade em descompasso, em que pessoas vivem na era da informação instantânea, com seus aparatos tecnológicos, enquanto que outras não têm acesso à escola com as mais básicas condições físicas, como por exemplo, uma biblioteca.

Quando pensamos em formação docente, precisamos considerar as várias realidades sociais do Brasil continental que abriga diversidades de etnias, de culturas, de identidades, de práticas sociais diferenciadas. Realidades que são de determinadas esferas, mas que não são de outras esferas sociais. Por outro lado, a educação escolar é direito universal das comunidades urbanas, das campesinas, das periferias, dos adultos que não são alfabetizados. Enfim, a educação é universal, assim como universal é a formação docente. Esta, por sinal, englobando diferentes modalidades.

Os diferentes contextos de formação docente, com as suas idiossincrasias, trazem-nos retratos de uma realidade de um todo. Diante dessa asserção, a experiência, que registramos, neste artigo, insere-se no Programa Institucional de Bolsas de Iniciação à Docência para a Diversidade - PIBID Diversidade, que tem como objetivo primordial o aperfeiçoamento da formação inicial de professores para o exercício da docência nas escolas indígenas e do campo. Esse programa é desenvolvido pela Coordenação de Aperfeiçoamento de Pessoal de Nível Superior (CAPES) em parceria com Universidades públicas e particulares, Secretarias Estaduais e Municipais de Educação Básica.

\subsection{A Licenciatura em Educação do Campo da Faculdade UnB Planaltina - DF}

A LEdoC, campus Planaltina - DF é uma licenciatura, com duração de 3.510 horas, 234 créditos, integralizados em oito semestres de Pedagogia da Alternância, tem como objetivo formar professores para atuarem nas escolas do Campo, que conheçam a realidade desse território. Pedagogia da Alternância significa que a licenciatura em sua metodologia pedagógica tem o Tempo Universidade (TU) e o Tempo Comunidade (TC). No TU, os estudantes permanecem na universidade durante sessenta dias, por semestre, em período integral, recebendo uma formação acadêmica em que há a interface com assuntos relacionados a temas de sua realidade territorial e social. O TC é o período em que os estudantes estão em sua comunidade, em atividades 
pessoais e, também, desenvolvendo atividades pedagógicas na escola do campo e em sua comunidade.

A LEdoC é um curso regular, cujo ingresso se dá mediante seleção que ocorre anualmente por meio de vestibular específico, até 2014, e a partir de 2015 por meio do Exame Nacional de Ensino Médio (ENEM). Em 2017, o curso voltou a ter um vestibular específico para seu acesso. Essa licenciatura habilita professores para atuarem nos anos finais do Ensino Fundamental e no Ensino Médio, nas áreas de Linguagens e Ciências da Natureza e da Matemática, além de formar para a gestão de processos educativos escolares e para a docência em uma das áreas de conhecimento e gestão de processos educativos nas comunidades. Essa licenciatura, em 2018, está na décima terceira turma com aproximadamente 250 educandos em atividade, distribuídos em três habilitações: Linguagens, Ciências da Natureza e Matemática.

Em 2007, foi implementada a LEdoC na Universidade de Brasília (UnB), com 60 vagas, com habilitação em Linguagens (Linguística, Artes e Literatura) e Ciências da Natureza e Matemática. O primeiro Projeto Político Pedagógico do Curso foi elaborado com a contribuição do Instituto Técnico de Capacitação e Pesquisa da Reforma Agrária (ITERRA), que tem sua sede em Veranópolis $\mathrm{RS}$, onde estudou a primeira turma da LEdoC, do início ao término do curso (2007-2010). A primeira turma da LEdoC formou, em educadores do campo, pessoas oriundas do Movimento Sem Terra, da Região Sul (Rio Grande do Sul, Paraná e Santa Catarina) e Sudeste (São Paulo e Rio de Janeiro).

As turmas dois, três e quatro da LEdoC receberam educandos oriundos da região Centro-Oeste (Mato Grosso, Mato Grosso do Sul, Goiás e Distrito Federal) e Sudeste (Minas Gerais: Buritis e Unaí), pessoas da agricultura familiar, de movimentos sociais, de quilombos, de assentados da Reforma Agrária, entre outros segmentos sociais.

A turma cinco foi composta de $80 \%$ de pessoas oriundas do maior sítio arqueológico quilombola da América Latina, situado ao norte de Goiás. Da sexta à décima terceira turma, há pessoas do campo e da cidade, que são do Distrito Federal, de Goiás e de Minas Gerais, algumas delas já exercem a docência em escolas do campo dessas regiões.

\section{Pibid Diversidade: fortalecendo a formação inicial na LEdoC}

O Pibid Diversidade está inserido na Licenciatura em Educação do Campo, da Universidade de Brasília, Campus Planaltina - DF, desde 2011, com o primeiro projeto desse programa, coordenado pela professora Mônica Castagna Molina, quando a LEdoC tinha quatro turmas, a primeira turma já finalizada e três turmas em andamento. Essas três turmas foram contempladas com cem bolsas de iniciação à docência, sendo cinquentas bolsas para a Área 
de Ciências da Natureza e Matemática (CIEMA) e cinquenta bolsas à Área de Linguagem.

A primeira experiência do Pibid Diversidade na LEdoC contemplou um projeto Interdisciplinar com dois subprojetos das duas Áreas: Linguagem e CIEMA (esse integrando Ciências da Natureza e Matemática). Esses subprojetos como um gênero discursivo foi materializado na práxis da sala de aula do campo, pelos bolsistas de iniciação à docência, que compreenderam o trabalho de planejamento conjunto realizado pelos coordenadores dessas duas áreas e seus respectivos supervisores, professores de escolas públicas do campo, grande parte em situação de contrato temporário.

No que diz respeito ao gênero discursivo, essa configuração, segundo Bazerman (2005, p. 11), "são fatos sociais emergentes na atividade de compreensão intersubjetiva em situações típicas em que se deve coordenar atividades e compartilhar significados, tendo em vista propósitos práticos”. Os subprojetos como gêneros discursivos quando foram lidos, compreendidos e colocados em práticas, por meio de atividades pedagógicas, pelos bolsistas de iniciação à docência, na sua formação inicial.

A segunda edição do Pibid Diversidade deu-se por meio da seleção ao Edital no 66, de 2013, destinado às Licenciaturas nas áreas Intercultural Indígena e Educação do Campo, em que a LEdoC foi contemplada com sessenta bolsas de iniciação à docência, seis para supervisão e duas para coordenação de área. Posteriormente, essa coordenação ganhou mais uma bolsa, ficando uma bolsa para Linguagem, uma para Ciências da Natureza e outra para Matemática. E, ainda, a bolsa de coordenação institucional.

O Projeto do Pibid Diversidade para a LEdoC se divide em dois subprojetos, sendo um de Linguagem e outro de Ciências da Natureza e Matemática. Porém, os subprojetos só dividem na configuração formal do gênero discursivo, visto que seu propósito prático busca ações interdisciplinares entre a Linguagem, a Ciências da Natureza e a Matemática. Esse projeto global tem como eixo norteador os letramentos múltiplos, que segundo Sousa (2016), são diferentes conhecimentos que se constroem e se sustentam conforme as variadas situações de leitura e de escrita, constituindose em práticas sociais e de letramento que circulam nas diferentes esferas da sociedade, proporcionando leituras, compreensões e interpretações dos saberes empíricos e científicos. Pois, ler e escrever, em diferentes esferas, de forma proficiente, é uma das chaves para a construção, para o refinamento e a transformação da educação.

Por isso, foi feito um investimento acentuado na leitura e na escrita, pois, foi percebido, no contexto da Educação do Campo, como em outros contextos da educação brasileira, uma lacuna muito grande nessas modalidades de conhecimento, em que grande parte da problemática é gerada porque a escola não investe na formação de leitores refinados e consequentemente escritores proficientes. 
Nessa concepção, compreendemos os letramentos múltiplos na dimensão da leitura, da interpretação e da ressignificação que se pode fazer das linguagens que envolvem as três áreas do conhecimento aqui expostas, extrapolando para a realidade sociocultural, política, ideológica e identitária, e, obviamente associados a conhecimentos de outras áreas das ciências, do senso comum e das experiências empíricas.

De acordo com a CAPES, o Pibid Diversidade, no contexto da Educação do Campo, visa incentivar a formação de docentes em nível superior; contribuir para a valorização do magistério do campo, integrar a educação básica e a superior; desenvolver metodologias específicas à diversidade sociocultural e linguística; desenvolver processos formativos que levem em consideração as diferenças culturais, que implicam no trabalho pedagógico.

Esses objetivos do Pibid Diversidade conversam com o projeto da LEdoC na formação de docentes para a Educação do Campo, possibilitando por meio das bolsas de iniciação que estudantes da LEdoC possam ter acesso, com mais facilidade, às escolas do campo desde o início da sua formação. Isso garante a almejada práxis que se busca na formação do educador do campo.

É fato, o Pibid Diversidade da LEdoC promove a integração entre ensino básico e superior por meio de suas ações pedagógicas planejadas, de forma interdisciplinar, e facilitadas pela metodologia da Alternância, que busca a interação em entre Tempo Universidade, conhecimento acadêmico, e Tempo Comunidade, inserção orientanda na escola e na comunidade. Esses tempos em duas faces integradas promovem a leitura acadêmica e a leitura de mundo (FREIRE, 2008), isto é, a leitura da realidade social, que talvez não fosse vista sem as especificidades das leituras acadêmico-científicas. De acordo com Machado:

\begin{abstract}
O PIBID Diversidade da LEdoC/UnB oferece aos educandos a oportunidade de envolver-se mais efetivamente com as práticas docentes durante o período de sua graduação, participando de ações concretas nas escolas (planejamento, coordenação, regência, projetos, reforço escolar, interação com a comunidade, preparação de material didático) e, principalmente fazendo integração com o estágio docente, de acordo com a realidade específica de cada escola do campo, onde os bolsistas do PIBID atuam. (2016, p. 31).
\end{abstract}


culturais e identitários. Esse fato pode ser comprovado no livro "Letramentos Múltiplos e Interdisciplinaridade na Licenciatura em Educação do Campo", resultado de ações do Pibid Diversidade, com o Observatório da Educação, que foi lançado no início de 2017, Faculdade UnB Planaltina. Que para Molina, o livro desvela:

as potencialidades destas novas políticas de formação de educadores, ao nos trazer, como protagonistas dos textos, educadores camponeses, atuando nas escolas das áreas de Reforma Agrária; nos quilombos, nas áreas de agricultura familiar tradicional, refletindo, criticamente, sobre suas próprias realidades e sobre suas práticas educativas, em diferentes áreas do conhecimento. (2016, p. 5).

3.1 A abrangência do Pibid Diversidade: da Faculdade UnB Planaltina - DF a outros territórios.

O Pibid Diversidade contemplou os estudantes da Licenciatura em Educação do Campo, da Faculdade UnB Planaltina - DF no fortalecimento da formação inicial, visto que nesse curso estão pessoas oriundas do campo que dependem desse território para viver, buscando nele sua sobrevivência como a soberania alimentar. Tiveram uma educação básica muito precária em escola com muitas limitações pedagógicas e físicas. Pedagógicas, porque a maioria das pessoas do campo estuda em contexto onde os professores geralmente são leigos, estão na condição de professores de contrato temporário, com pouca ou nenhuma experiência na Educação do Campo. Na dimensão física, escolas sem bibliotecas, distantes das moradias dos estudantes, com poucas ou com uma sala de aula.

Os educandos na LEdoC, por meio dos múltiplos letramentos que alcançam conhecimentos diferentes áreas (tais como a Filosofia, Educação do Campo, Teoria Pedagógica, Problemas Brasileiros, Linguagens etc.) conseguem ter uma formação bastante ampla e multidisciplinar.

Os subprojetos do Pibid seguem essa linha interdisciplinar na formação dos bolsistas desse programa, tendo como eixo os múltiplos letramentos que consistem em diferentes conhecimentos acadêmicos que são por meio da leitura e da escrita no Tempo Universidade. Os conhecimentos do Tempo Universidade são geralmente conduzidos ao Tempo Comunidade por meio da inserção orientada nas escolas do campo e por meio de atividades nas comunidades, tais como seminários, encontros, festejos, projetos e eventos culturais. 
O trabalho com o Pibid Diversidade está localizado nos dois Tempos: Universidade e Comunidade. No primeiro, os estudantes participam de planejamentos, reuniões, seminários, oficinas voltadas à sua formação para atuação no Tempo Comunidade onde vão atuarem como bolsistas do Pibid nas escolas do campo, semanalmente, por 8 horas.

Durante os 4 anos da atuação do Pibid Diversidade, foram contempladas cerca de 25 escolas nos territórios de Planaltina - DF; Flores, Cavalcante, Monte Alegre, Virgilândia, Vale da Esperança, Ipiranga, Diadema, Teresina, Fazenda Coco - GO, Comunidades Quilombolas do norte de Goiás; e Buritis, Unaí e Formoso - MG. Os mais de 120 bolsistas, em rodízio, que passaram por ele tiveram a oportunidade de interagir com a educação básica do campo dentro de seus conflitos, problemas pedagógicos, de estrutura física, de soberania alimentar, mas, outro lado, aproveitaram da cultura e da identidade de povos do campo e quilombolas, comunidades de onde esses bolsistas fazem parte.

Contudo, na prática das escolas, na dinâmica da sala de aula puderam ler de várias formas o que é a educação do campo, agora do outro lado, do lado do professor, em uma experiência ímpar. Muitos dos bolsistas do Pibid Diversidade eram/são professores de contrato de escolas do campo, situação adversa a que propunha o projeto da CAPES. Isso se dá porque a Educação do Campo é complexa com realidades idiossincráticas, em que uma criança caminha por 7 quilômetros para chegar à escola com fome, cansada e com o pés sujos, quando o transporte escolar falha. Onde a merenda não foi suficiente por falta de verba ou por mau uso dessa verba. Onde há as classes multisseriadas, onde estudam discentes do $1^{\circ}, 2^{\circ}, 3^{\circ}$ e $4^{\circ}$ anos, exigindo do professor um esforço ultra-humano e muitas habilidades pedagógicas que buscam apenas, muitas vezes, na formação de um ensino médio.

Essa realidade está presente nas escolas do norte de Goiás, principalmente, e a podemos conhecê-las nas nossas viagens de visita a algumas comunidades. O Pibid Diversidade nos fez enxergar situações que fazem parte do cenário educacional do Brasil, de tanto descompasso. Essa realidade ensinou muito aos bolsistas de iniciação à docência, supervisores, coordenadores de área e coordenação institucional, colaboradores voluntários e pesquisadores do Pibid Diversidade e também estudantes, coordenadores e professores de escolas do campo.

Nos 4 anos de Pibid na LEdoC, os bolsistas tiveram a oportunidade de observar a escola, de fazer planejamento, ministrar aulas, acompanhar estudantes no reforço escolar, promover trabalho de leitura e de escrita, realizar feiras de ciências de agroecologia, aulas in situ, seminários, interação entre escola e família entre outras atividades. 
Na realidade, o Pibid Diversidade fez com que nós, professores, de universidade tivéssemos contato muito mais de perto com realidades complexas da educação brasileira. Essa experiência, de uma leitura muito refinada, é muito importante para nossa ação-reflexão-ação que nos guia em uma formação docente mais realista, considerando a diversidade brasileira. Conforme Almeida:

[...] as leituras do professor são relevantes para a constituição de sua identidade profissional, elementos constitutivos da profissão docente, pois estão vinculadas à representação das práticas pedagógicas por eles construídas e podem produzir efeitos significativos em seu desempenho profissional que se reflete diretamente e sua práxis. (2001, p. 119).

A experiência do Pibid Diversidade promoveu a integração entre a universidade, a Educação Básica no que compreende aos estudantes da escola e aos professores e diretores de escolas do campo, principalmente de escolas quilombolas. Oportunizou aos egressos da LEdoC, ex-bolsistas de iniciação à docência, professores em regência, que fossem também supervisores desse programa em suas comunidades campesinas. Assim, puderam participar de experiências da formação inicial e da atuação em sala de aula, orientando os novos bolsistas. A LEdoC e as escolas do campo tiveram um ganho pedagógico enorme com tais experiências.

$\mathrm{Na}$ voz dos bolsistas do Pibid, temos narrativas do que é esse programa para a formação docente, como mostram os discursos, a seguir:

É muito gratificante poder falar do PIBID. Há 18 meses atrás quando entrei no PIBID diversidade, não imaginava os benefícios que teria com ele." (A., supervisora).

Ele está sendo muito importante na minha formação me incentivando e trazendo melhorias para a minha formação como educanda, pois eu tinha muita dificuldade para entrar em sala de aula e com o projeto me ajudou muito, pois ele tem uma parcela na responsabilidade do meu amadurecimento intelectual e minha vivência em sala de aula. (At., Iniciação à docência).

O Programa Institucional de Bolsa de Iniciação à Docência PIBID foi de suma importância para a minha formação, pois, através dele tivemos a oportunidade de ter uma maior contribuição na nossa formação enquanto docentes. Esse projeto tem um grande valor no processo de iniciação a sala de aula, é por meio dele que muitos educandos têm o contato com a realidade de uma sala de aula. (N., Supervisora). 
Os seminários do PIBID foram de grande valia, visitamos cidades históricas e turísticas. Fiz parte de um seminário que não era da minha comunidade, porém, foi muito produtivo; nos momentos históricos que o mundo está vivenciando, uma crise seja ela no excesso de água (inundação) ou escassez (seca) no qual o desequilibro ambiental pode ocorrer fatos para o risco da economia mundial, tais como mudanças climáticas que ameaçam a economia, política e meio ambiente, causando retroalimentação. (Cl. Iniciação à docência,).

O PIBID é um programa de iniciação à docência muito importante para aqueles que como eu, estão em formação acadêmica. Através do programa pude ampliar minha prática e também compreender como a pesquisa pode ser aplicada na docência. $O$ fato do programa ser subsidiado é de extrema importância pois, existem coisas a se considerar, uma delas é que existem custos de locomoção e de material, por exemplo, papel, impressão e tinta. (K. Iniciação à docência ).

A intenção do programa é unir as secretarias estaduais e municipais de educação e as universidades públicas, a favor da melhoria do ensino nas escolas públicas em que o Índice de Desenvolvimento da Educação Básica (IDEB) esteja abaixo da média nacional, de 4,4. Entre as propostas do PIBID está o incentivo à carreira do magistério nas áreas da educação básica com maior carência de professores com formação específica: ciência e matemática de quinta a oitava anos do ensino fundamental, nas disciplinas de física, química, biologia e matemática para o ensino médio.Foi então que fui inserida na minha unidade escolar o programa, com o objetivo de ajudar e conscientizar todos da unidade escolar e da comunidade com palestras, debates, oficinas, atividades escolares desenvolvidas com os próprios alunos abordando temas que foi do interesse de todos. Um dos temas trabalhado foi sobre água. Fiz pesquisas sobre a água na minha escola e comunidade. (L., Iniciação à docência ).

Eu, A. E. P., graduanda em Matemática do curso de Licenciatura da Educação do Campo e bolsista do Pibid Diversidade, tenho a honra de falar que foi um projeto que contribuiu muito para minha inserção na Escola e para meu estágio. E com o benefício fui capaz de comprar materiais didáticos, lanches, e ajudar nos transportes para as saídas de campo, e nas despesas da casa enquanto trabalhava no projeto. Depois de ingressar no Pibid diversidade, posso afirmar que foi proveitoso para nós graduandos, e para os alunos do ensino fundamental e médio das Escolas das comunidades quilombolas do município de Teresina de Goiás. (A., Iniciação à docência)

O Programa Institucional de Bolsa de Iniciação à Docência para a Diversidade é, portanto, uma contribuição importante para desenvolvimento de ações interdisciplinares e da ligação da escola com a vida. Por meio da LEDOC/ PIBID o (a) educador (a) desenvolve ações e projetos com objetivos de fortalecer a 
comunidade, valorizando sua cultura e suas formas de vivências por meio das atividades realizadas. (L., Supervisora).

O Programa Institucional de Bolsa de Iniciação à Docência (PIBID) tem cumprido um papel indispensável em minha formação, quanto estudante de Licenciatura em Educação do Campo (LEdoC), da Universidade de Brasília (UnB). A inserção na escola para os estudantes de Licenciatura é imprescindível. Esse primeiro contato com a escola foi bastante facilitado no momento em que passamos a ser bolsistas. Aproximação do estudante à escola permite uma melhor formação, uma vez que dentro desse processo acontece o uso da práxis, isto é, a junção entre teoria e prática. De um lado a teoria aprendida na universidade, de outro, a prática vivenciada no ambiente escolar. Para nós, estudantes da Licenciatura em Educação do Campo, esse método é crucial. (Lu. Iniciação à docência.)

Esses discursos de bolsistas de iniciação à docência e supervisoras, que são também professoras de escolas do campo, mostram o significado do Pibid Diversidade para a formação de educadores para as escolas do campo e a importância desse programa ao cenário da educação pública brasileira.

\section{CONSIDERAÇÕES}

O Pibid Diversidade, Edital 66, na Licenciatura em Educação do Campo, da Faculdade UnB Planaltina - DF, contribuiu de forma fortalecedora à formação inicial de cerca de 120 estudantes, os quais estiveram em interação com mais de 25 escolas do campo do Distrito Federal, de Goiás e de Minas Gerais, pois a LEdoC é um curso de formação docente, de Pedagogia da Alternância, que possibilita a inclusão de pessoas de lugares distantes do campo ter acesso à Educação Superior e viu no Pibid uma forma de manter essa inclusão, investindo na formação docente em lugares de acesso complexo.

Esse programa oportunizou com seus recursos a inserção de estudantes em formação no contexto da escola do campo com suas problemáticas de toda a ordem. Também, foi um meio de integralização da universidade e da educação básica, do ensino, da pesquisa e da extensão.

No que se refere à práxis pedagógica, o Pibid Diversidade por meio dos subprojetos de Linguagens, Ciências da Natureza e Matemática a promoveu nos diferentes contextos de letramentos múltiplos: planejamento, coordenação, aulas in situ, regência, observação, seminários, encontros culturais, materiais pedagógicos etc. 


\section{REFERÊNCIAS}

ALMEIDA, Ana Lúcia de Campos. O professor-leitor, sua identidade e sua práxis. In: KLEIMAN, Angela B. (Org.) A formação do professor: perspectivas da linguística aplicada. São Paulo: Mercado de Letras, 2001.

BAZERMAN, Charles. Gêneros textuais, tipificação e interação. São Paulo: Cortez, 2005.

BORTONI-RICARDO, Stella Maris. Manual de Sociolinguística. São Paulo:

Contexto, 2014.

CALDART, Roseli S. Por uma educação do campo: traços de uma identidade em construção. In: KOLLING, Cerioli; CALDART, Roseli S. (Orgs). Educação do Campo: identidade e políticas públicas. Brasília: Coleção por uma Educação do Campo, 2002.

CALDART, Roseli S. et. al. (Orgs). Dicionário da Educação do Campo. Rio de Janeiro/São Paulo: Expressão Popular, 2012.

FREIRE, Paulo. A importância do ato de ler. 49ª ed. São Paulo: Cortez, 2008.

KLEIMAN, Angela B. (Org.). A formação do professor: perspectivas da linguística aplicada. São Paulo: Mercado de Letras, 2001.

MACHADO, Catarina dos Santos. As contribuições do Pibid Diversidade à formação docente da LEdoC da Universidade de Brasília. In: SOUSA, Rosineide Magalhães de et al (Orgs). Letramentos Múltiplos e Interdisciplinaridade na Licenciatura em Educação do Campo. Brasília: DEX/UnB, 2016.

MOLINA, Mônica C.; SÁ, Lais M. Licenciatura em Educação do Campo: registros e reflexões a partir das experiências-piloto (UFMG; UnB; UFBA e UFS). Belo Horizonte: Autêntica Editora, 2011.

MOLINA, Mônica C.; HAGE, Salamão. Política de formação de educadores do campo no contexto de expansão da educação do campo no contexto de expansão da educação superior. Revista Educação em Questão, Natal, v.51, n. 37, p. 121-146. Jan/abr., 2015.

MOLINA, Mônica C. Prefácio. In: SOUSA, Rosineide Magalhães de et al (Orgs). Letramentos Múltiplos e Interdisciplinaridade na Licenciatura em Educação do Campo. Brasília: DEX/UnB, 2016.

PPP. Projeto Político Pedagógico. Universidade de Brasília (UnB), Faculdade de Planaltina (FUP), Licenciatura em Educação do Campo (LEdoC). Brasília: UnB, 2009.

ROJO, Roxane. Letramentos múltiplos, escola e inclusão social. São Paulo: Parábola Editorial, 2006.

SOUSA, Rosineide Magalhães de et al (Orgs). Letramentos Múltiplos e Interdisciplinaridade na Licenciatura em Educação do Campo. Brasília: DEX/UnB, 2016. 